\title{
The powerful association of angiotensin-converting enzyme insertion/deletion polymorphism and idiopathic recurrent pregnancy loss
}

\author{
Evren Gumus \\ Department of Medical Genetics, Faculty of Medicine, University of Harran, Sanliurfa, Turkey
}

\begin{abstract}
Objectives: Idiopathic recurrent pregnancy loss (IRPL) is one of the most troublesome complications of pregnancy. Several researches were also conducted to search the possible association with ACE I/D polymorphism and IRPL. In the light of these reports, this case-control study was investigated to genotypes and alleles of $A C E$ I/D polymorphism in IRPL group and control group.

Material and methods: Overall, 1176 subjects (1007 cases, 169 controls) were investigated. Allele genotype distributions were determined by PCR method in both groups. Differences in genotype and allele frequencies between groups were investigated by Pearson chi-square tests. The odds ratio (OR) and $95 \%$ confidence intervals ( $95 \% \mathrm{Cl}$ ) were also determined.

Results: For the $A C E \mathrm{I} / \mathrm{D}$ polymorphism I and D allele frequencies were in the control and case groups respectively; 49.4 and $41.6 \%, 50.6$ and $58.4 \%$. The genotypes of $A C E$ for I/D observed in control and case group respectively were as follows; II (27.2 and 17.9), ID (44.4 and 47.4) and DD (28.4 and 34.7). Regarding the distribution of D allele and genotypes containing D allele, we observed significant statistical differences between case and control groups.

Conclusions: Our results showed that the $A C E \mathrm{I} / \mathrm{D}$ polymorphism was associated with IRPL, and that women that carried DD or ID genotypes had a $72 \%$ elevated risk of developing IRPL than women with the ll genotype (OR (95\% Cl): $1.72(1.181-2.5)$ ). This odds ratio was found to be 1.61 in a case-control study and 1.28 in a meta-analysis study compiling 11 separate studies, which is consistent with our study data.
\end{abstract}

Key Words: ACE, polymorphism, recurrent miscarriages, pregnancy loss

\section{INTRODUCTION}

Idiopathic recurrent pregnancy loss (IRPL) is one of the most troublesome complications of pregnancy. IRPL is defined differently by several groups. The diversified description is as follows: loss of two or more consecutive pregnancies before four months and three or more sequent pregnancy loss before the 22 nd-24rd week of pregnancy [1-3]. IRPL affects approximately $1-5 \%$ of women who are pregnant, according to the 'IRPL definition' of two or three consecutive pregnancy loss. This percentage increases with age [4]. Currently, several well-known risk factors of recurrent miscarriage are described: chromosomal abnormalities, polycystic ovary syndrome, thrombophilia, hypothyroidism, anatomic anomalies, endocrine disturbances, obesity, infections, and environmental and nutritional factors [5]. However, more than $50 \%$ of women with IRPL have no precise reason of pregnancy loss [6]. Genetic causes account for only $2-5 \%$ of the defined causes [7]. Despite this low level, many different studies have been conducted on genetic changes in the etiology of IRPL. The most marked relationship between these studies is related to numerical and structural chromosome anomalies. However, many gene polymorphisms have also been investigated, especially these related to coagulation cascade, as the successful pregnancy is dependent on a sensitive balance between fibrinolysis and coagulation. Until this date, about the topic the most studied genes and 
polymorphisms were plasminogen activator inhibitor-1 (PAl1) $4 \mathrm{G} / 5 \mathrm{G}$, methylenetetrahydrofolate reductase (MTHFR) C677T, factor V-Leiden (G1691A), factor-2 20210G > A and angiotensin-converting enzyme (ACE) insertion/deletion (I/D) polymorphism [7-9]. The ACE is located on long arm of chromosome of 17 with 25 introns and 26 exons and contains 21 kilobases $(\mathrm{kb})$ of genomic DNA. ACE plays a key role in the rennin-angiotensin-aldosterone system (RAAS) and is related in the transformation of angiotensin I to active angiotensin II, a powerful vasoconstrictor [10]. An I/D polymorphism of the ACE forming of the insertion or deletion of a 287 basepair (bp) Alu sequence component in intron 16 is associated with the serum ACE level (rs4340). The existence of the D/D genotype or $D$ allele is associated with high serum and plasma ACE activity. The D/D genotype also increases procuration of angiotensin II from angioten$\sin I$ and is associated with elevated levels of PAI-1, which result in the decreased levels of fibrinolysis. Furthermore, ACE degrades bradykinin, a very potent vasodilator [11]. Several researches were also conducted to search the possible association with ACE I/D polymorphism and IRPL. The potential role of ACE I/D polymorphism in IRPL pathogenesis has been controversial [3, 9, 12-15].

\section{Objectives}

This current case-control study was investigated to genotypes and alleles of ACE I/D polymorphism in two groups from the south-eastern part of Turkey. The case group with two unexplained consecutive pregnancy losses and the control group with at least one live birth and no history of pregnancy loss.

\section{MATERIALS AND METHODS}

Overall, 1176 subjects (1007 cases, 169 controls) were investigated between October 2016 and August 2018. Of those, 1007 women had a history of $\geq 2$ consecutive pregnancy losses and 169 fertile women had at least one live birth and no history of pregnancy loss. For this purpose, the participants with following evidence were excluded from each group; structural uterine abnormality, chromosomal abnormalities, hormonal imbalance (TSH, FSH, LH, prolactin), anti-nuclear antibodies, antiphospholipid antibodies and lupus anticoagulant. All women were from Sanliurfa province in the south-east of Turkey. The study was approved by the Institutional Review Board of Faculty of Medicine in Harran University (Ethics Committee Document Number: 04.01.2018/01-12) and the study was conducted in accordance with 2013 Declaration of Helsinki. All women included in the study signed the informed consent form. Complete blood samples were taken from the antecubital vein via vacutainer tubes comprising ethylenediaminetetraacetic acid (EDTA) (BD, Franklin Lakes, NJ). DNA was iso- lated from blood samples using Magpurix Blood DNA Extraction Kit 200 (Zinexts LSC, New Taipei City, Taiwan [R.O.C.]). Quantitative-purity determinations and fluorometry analysis were performed (NanoDrop 8000, Thermo-Fisher Scientific, DE, USA). To analyze ACE I/D polymorphism, genomic DNA was amplified by polymerase chain reaction (PCR) using specific primers: forward: 5'-CTGGAGACCACTCCCATCCTTTCT-3'; reverse:5' GATGTGGCCATCACATTCGTCAGAT-3' (Sentegen Biotech, Ankara, TR). The PCR method used for this polymorphism was performed as previously described [16]. DNA fragments were separated by $3 \%$ agarose electrophoresis and described by ethidium bromide staining. Three types of ACE PCR products were described a $190 \mathrm{bp}$ band corresponding to the D/D genotype, a 490 bp band corresponding to I/I genotype, or a compound of 190 and $490 \mathrm{bp}$ bands corresponding to the I/D genotype. Allele and genotype frequencies were checked for deviation from Hardy-Weinberg equilibrium by Pearson chi-square analysis. Differences in genotype and allele frequencies between groups were investigated by Pearson chi-square tests. The odd ratio (OR) and $95 \%$ confidence intervals $(95 \% \mathrm{Cl}$ ) were also determined. All statistical data were analyzed using statistical package for social sciences (SPSS) software version 23.0 (IBM SPSS, Chicago, IL, USA) program. For all tests $\mathrm{p}<0.05$ was considered as significant.

\section{Results}

The mean age of the control group and case group was $26.41 \pm 6.29$ years (ranged between 19-45, median 26), and $25.88 \pm 5.76$ years (ranged between 19-43, median 25), respectively. There was no significant difference between the case and control groups ( $p>0.05)$. For the ACE I/D polymorphism I and $D$ allele frequencies were in the control and case groups respectively; 49.4 and $41.6 \%, 50.6$ and $58.4 \%$. The genotypes of ACE for I/D observed in control and case group respectively were as follows; II (27.2 and 17.9), ID (44.4 and 47.4) and DD (28.4 and 34.7). The genotype and allele frequencies in the control and case groups were checked for deviation from Hardy-Weinberg equilibrium. No deviation was observed (Tab. 1). The odds ratio, confidence interval, chi-square test and $p$ value are displayed in Table 1. The most frequent genotype was ID in both groups. Regarding the distribution of $\mathrm{D}$ allele and genotypes containing $\mathrm{D}$ allele, we observed significant statistical differences between case and control groups.

\section{DISCUSSION}

In this study, we have tried to examine ACE I/D polymorphism allelic frequencies and genotypes and its association with IRPL among south-eastern Turkish women. ACE I/D polymorphism has so far been associated with many conditions such as stroke, coronary heart disease, diabetic nephropathy, 
Table 1. The allelic frequencies and genotype of ACE I/D polymorphisms in both groups

\begin{tabular}{|c|c|c|c|c|c|}
\hline \multicolumn{2}{|c|}{$\begin{array}{l}\text { Tests for deviation from 'Hardy- } \\
\text { Weinberg' equilibrium }\end{array}$} & \multicolumn{4}{|c|}{ Tests for association (C.I.: 95\% confidence interval) } \\
\hline Controls & Cases & $\begin{array}{l}\text { Allele frequency } \\
\text { difference }\end{array}$ & Heterozygous & Homozygous & Allele positivity \\
\hline & & {$[\mathrm{l}]-[\mathrm{D}]$} & [II] - [ID] & {$[I I+I D]-[D D]$} & {$[I I]-[I D+D D]$} \\
\hline$p=0.1443$ & $p=0.4305$ & $\begin{array}{l}\text { Odds_ratio }=1.373 \\
\text { C.I. }=[1.090-1.730] \\
\text { chi2 }=7.29 \\
p=0.00694\end{array}$ & $\begin{array}{l}\text { Odds_ratio }=1.625 \\
\text { C.I. }=[1.084-2.437] \\
\text { chi2 } 2=5.59 \\
p=0.01806\end{array}$ & $\begin{array}{l}\text { Odds_ratio }=1.863 \\
\text { C.I. }=[1.197-2.901] \\
\text { chi2 }=7.75 \\
p=0.00537\end{array}$ & $\begin{array}{l}\text { Odds_ratio }=1.718 \\
\text { C.I. }=[1.181-2.500] \\
\text { chi2 }=8.14 \\
p=0.00433\end{array}$ \\
\hline
\end{tabular}

athletic performance, hypertension, preeclampsia and IRPL $[15,17,18]$. The probable association between IRPL and ACE I/D polymorphism is based on the theory that degenerated hemostasis, excess fibrin accumulations in spiral arteries and impedes perfusion secondary to platelet aggregation could lead to pregnancy loss. The D allele was shown to be associated with a high level of ACE in serum, which enhances the formation of angiotensin II from angiotensin I, thus increasing the risk of thrombotic episodes. Some studies have reported a link between the $D$ allele and risk of thrombosis $[11,13,15]$. Data by several regions demonstrated that the D allele and DD genotype leads to a high PAI-1 level which reduced fibrinolysis and thus correlated with an increased risk of IRPL $[9,12,15]$. Many studies have been managed to explore the link between ACE I/D polymorphism alleles and genotypes and IRPL, but the results of these studies differ from each other [13-15, 19-24]. Our results showed that the ACE I/D polymorphism was associated with IRPL, and that women that carried DD or ID genotypes had a $72 \%$ elevated risk of developing IRPL than women with the Il genotype [OR (95\% Cl): $1.72(1.181-2.5)]$. This odds ratio was found to be 1.61 in a case-control study and 1.28 in a meta-analysis study compiling 11 separate studies, which is consistent with our study data $[13,25]$. In a study conducted in our country in 2012, the relationship between ACE I/D polymorphism and IRPL was found to be significant at a high level [26].

\section{CONCLUSIONS}

The genotype and allele distribution of the ACE I/D polymorphism influenced the risk of IRPL in the south-east of Turkey, confirming the findings in the north-west of Turkey. The most valuable aspect of our work is that it has a large sample and is a prospective case-control study. Examination of the PAI-1 level could add value to this study, but unfortunately, this was not possible. Polymorphism studies in different societies, with a high number of participants, will undoubtedly become more valuable with the work to be done in the coming years.

\section{Conflict of Interest.}

The authors declare no conflicting of interest.

\section{REFERENCES}

1. Stephenson $M$, Kutteh $W$. Evaluation and management of recurrent early pregnancy loss. Clin Obstet Gynecol. 2007; 50(1): 132-145, doi: 10.1097/GRF.0b013e31802f1c28, indexed in Pubmed: 17304030.

2. Jauniaux $E$, Farquharson RG, Christiansen $O B$, et al. Evidence-based guidelines for the investigation and medical treatment of recurrent miscarriage. Hum Reprod. 2006; 21(9): 2216-2222, doi: 10.1093/humrep/del150, indexed in Pubmed: 16707507.

3. Kurzawińska G, Barlik M, Drews K, et al. Coexistence of ACE (I/D) and PAI$1(4 \mathrm{G} / 5 \mathrm{G})$ gene variants in recurrent miscarriage in Polish population. Ginekol Pol. 2016; 87(4): 271-276, doi: 10.17772/gp/62203, indexed in Pubmed: 27321098.

4. Larsen EC, Christiansen $\mathrm{OB}$, Kolte $\mathrm{AM}$, et al. New insights into mechanisms behind miscarriage. BMC Med. 2013; 11: 154, doi: 10.1186/17417015-11-154, indexed in Pubmed: 23803387.

5. Baek KH, Lee EJ, Kim YS. Recurrent pregnancy loss: the key potential mechanisms. Trends Mol Med. 2007; 13(7): 310-317, doi: 10.1016/j. molmed.2007.05.005, indexed in Pubmed: 17574920.

6. Li J, Chen $\mathrm{Y}, \mathrm{Wu} \mathrm{H}$, et al. Apolipoprotein $\mathrm{E}$ (Apo E) gene polymorphisms and recurrent pregnancy loss: a meta-analysis. J Assist Reprod Genet. 2014; 31(2): 139-148, doi: 10.1007/s10815-013-0128-5, indexed in Pubmed: 24221911.

7. Ford HB, Schust DJ. Recurrent pregnancy loss: etiology. Diagnosis and therapy. Rev Obstet Gynecol. 2009; 2(2): 76-83, indexed in Pubmed: 19609401.

8. Chatzidimitriou M, Chatzidimitriou D, Mavridou M, et al. Thrombophilic gene polymorphisms and recurrent pregnancy loss in Greek women. Int J Lab Hematol. 2017; 39(6): 590-595, doi: 10.1111/ijlh.12703, indexed in Pubmed: 28603947.

9. Choi YiS, Kwon H, Kim JiH, et al. Haplotype-based association of ACE I/D, AT1R 1166A $>C$, and AGT M235T polymorphisms in renin-angiotensin-aldosterone system genes in Korean women with idiopathic recurrent spontaneous abortions. Eur J Obstet Gynecol Reprod Biol. 2011; 158(2): 225-228, doi: 10.1016/j.ejogrb.2011.04.028, indexed in Pubmed: 21636204

10. Rigat $B$, Hubert $C$, Alhenc-Gelas $F$, et al. An insertion/deletion polymorphism in the angiotensin l-converting enzyme gene accounting for half the variance of serum enzyme levels. J Clin Invest. 1990; 86(4): 1343-1346, doi: 10.1172/JCl114844, indexed in Pubmed: 1976655.

11. Fatini C, Gensini F, Battaglini B, et al. Angiotensin-converting enzyme DD genotype, angiotensin type 1 receptor CC genotype, and hyperhomocysteinemia increase first-trimester fetal-loss susceptibility. Blood Coagul Fibrinolysis. 2000; 11 (7):657-662, indexed in Pubmed: 11085286.

12. Bukreeva L, Grigorov A, Kiesewetter $\mathrm{H}$, et al. Association of angiotensin-converting enzyme intron 16 insertion/deletion polymorphism with history of foetal loss. J Renin Angiotensin Aldosterone Syst. 2009; 10(4): 237-240, doi: 10.1177/1470320309343813, indexed in Pubmed: 19717502.

13. Al-Mukaynizi FB, AlKhuriji A, Babay Z, et al. Lack of Association between Angiotensin Converting Enzyme I/D Polymorphism and Unexplained 
Recurrent Miscarriage in Saudi Arabia. J Med Biochem. 2016; 35(2): 166-173, doi: 10.1515/jomb-2015-0020, indexed in Pubmed: 28356877.

14. Heidari MM, Sheikholeslami M, Yavari M, et al.The association of renin-angiotensinogen system genes polymorphisms and idiopathic recurrent pregnancy loss. Hum Fertil (Camb). 2017 [Epub ahead of print]: 1-7, doi: 10.1080/14647273.2017.1388545, indexed in Pubmed: 29057680.

15. Fazelnia S, Farazmandfar T, Hashemi-Soteh SM. Significant correlation of angiotensin converting enzyme and glycoprotein Illa genes polymorphisms with unexplained recurrent pregnancy loss in north of Iran. Int J Reprod Biomed (Yazd). 2016; 14(5): 323-328, indexed in Pubmed: 27326417.

16. Kim JJu, Choi YM, Lee SKi, et al. The PAI-1 4G/5G and ACE I/D polymorphisms and risk of recurrent pregnancy loss: a case-control study. Am J Reprod Immunol. 2014; 72(6): 571-576, doi: 10.1111/aji.12302, indexed in Pubmed: 25078885.

17. Zhao J, Qin X, Li S, et al. Association between the ACE I/D polymorphism and risk of ischemic stroke: an updated meta-analysis of 47,026 subjects from 105 case-control studies. J Neurol Sci. 2014; 345(1-2): 37-47, doi: 10.1016/j.jns.2014.07.023, indexed in Pubmed: 25082780.

18. Rahimi Z. ACE insertion/deletion (I/D) polymorphism and diabetic nephropathy. J Nephropathol. 2012; 1(3): 143-151, doi: 10.5812/nephropathol.8109, indexed in Pubmed: 24475405.

19. Shakarami F, Akbari MT, Zare Karizi S. Association of plasminogen activator inhibitor-1 and angiotensin converting enzyme polymorphisms with recurrent pregnancy loss in Iranian women. Iran J Reprod Med. 2015; 13(10): 627-632, indexed in Pubmed: 26644791.

20. Dossenbach-Glaninger A, van Trotsenburg M, Schneider B, et al. ACE I/D polymorphism and recurrent first trimester pregnancy loss: interaction with SERPINE1 4G/5G and F13 Val34Leu polymorphisms. Br J Haematol. 2008; 141(2): 269-271, doi: 10.1111/j.1365-2141.2008.07058.x, indexed in Pubmed: 18318764.

21. López-Jiménez JJ, Porras-Dorantes Á, Juárez-Vázquez Cl, et al. Molecular thrombophilic profile in Mexican patients with idiopathic recurrent pregnancy loss. Genet Mol Res. 2016; 15(4), doi: 10.4238/gmr.15048728, indexed in Pubmed: 27808369.

22. Sun L, LvH, WeiW, et al. Angiotensin-converting enzyme $D / I$ and plasminogen activator inhibitor-1 4G/5G gene polymorphisms are associated with increased risk of spontaneous abortions in polycystic ovarian syndrome. J Endocrinol Invest. 2010;33(2): 77-82, doi: 10.1007/BF03346557, indexed in Pubmed: 19636212.

23. Ivanov P, Konova E, Komsa-Penkova R, et al. [Preplacentation pregnancy loss in cases of angiotensin-converting enzyme insertion/deletion polymorphism]. Akush Ginekol (Sofiia). 2014; 53(4): 12-16, indexed in Pubmed: 25510065.

24. Vettriselvi V, Vijayalakshmi K, Paul SFD, et al. ACE and MTHFR gene polymorphisms in unexplained recurrent pregnancy loss. J Obstet Gynaecol Res. 2008; 34(3): 301-306, doi: 10.1111/j.1447-0756.2008.00 792.x, indexed in Pubmed: 18588608.

25. Su MT, Lin SH, Chen YC, et al. Genetic association studies of ACE and PAl-1 genes in women with recurrent pregnancy loss. Thrombosis and Haemostasis. 2012; 109(1): 8-15, doi: 10.1160/th12-08-0584.

26. Ozdemir O, Yenicesu Gl, Silan F, et al. Recurrent pregnancy loss and its relation to combined parental thrombophilic gene mutations. Genet Test Mol Biomarkers. 2012; 16(4): 279-286, doi: 10.1089/gtmb.2011.0191, indexed in Pubmed: 22047507. 